\title{
Use of nanotechnology for infectious disease diagnostics: application in drug resistant tuberculosis
}

Roshanthi Eranga Karunaratne ${ }^{1 *}$ D, Lahiru A. Wijenayaka ${ }^{2,3}$, Sandya Sulochana Wijesundera ${ }^{4}$, K. M. Nalin De Silva ${ }^{2,5}$, Chamila Priyangani Adikaram ${ }^{6}$ and Jennifer Perera'

\begin{abstract}
Background: The increased transmission of multidrug-resistant (MDR) tuberculosis (TB) poses a challenge to tuberculosis prevention and control in Sri Lanka. Isoniazid (INH) is a key element of the first line anti tuberculosis treatment regimen. Resistance to INH may lead to development of MDR TB. Therefore, early detection of INH resistance is important to curb spread of resistance. Due to the limited availability of rapid molecular methods for detection of drug resistance in Sri Lanka, this study was aimed at developing a simple and rapid gold nanoparticle (AuNP) based lateral flow strip for the simultaneous detection of the most common INH resistance mutation (katG S315 T, 78.6\%) and Mycobacterium tuberculosis (MTb).
\end{abstract}

Methods: Lateral flow strip was designed on an inert plastic backing layer containing a sample pad, nitrocellulose membrane and an absorption pad. Biotin labeled 4 capture probes which separately conjugated with streptavidin were immobilized on the nitrocellulose. The test sample was prepared by multiplex PCR using primers to amplify codon 315 region of the $k a t G$ gene and MTb specific 156110 region. The two detection probes complementary to the $5^{\prime}$ end of each amplified fragment was conjugated with gold nanoparticles $(20 \mathrm{~nm})$ and coupled with the above amplified PCR products were applied on the sample pad. The hybridization of the amplified target regions to the respective capture probes takes place when the sample moves towards the absorption pad. Positive hybridization is indicated by red colour lines.

Results: The three immobilized capture probes on the strip (for the detection of $\mathrm{TB}$, kat $G$ wild type and mutation) were 100 and $96.6 \%$ specific and 100 and $92.1 \%$ sensitive respectively.

Conclusion: The AuNP based lateral flow assay was capable of differentiating the specific mutation and the wild type along with MTb identification within $3 \mathrm{~h}$.

Keywords: Isoniazid, MDR TB, Gold nanoparticles, Mycobacterium tuberculosis

\section{Background}

Tuberculosis (TB) is an infectious disease caused by the bacillus Mycobacterium tuberculosis (MTb) which remains a major global health problem, responsible for ill health and deaths among millions of people each year. The transmission of multidrug-resistant (MDR) TB poses a challenge to global tuberculosis prevention and control. MDR-TB, defined as

\footnotetext{
*Correspondence: erangark@yahoo.com

1 Department of Microbiology, Faculty of Medicine, University of Colombo, box 271, Kynsey Road, Colombo, PO 08, Sri Lanka

Full list of author information is available at the end of the article
}

resistance to at least rifampicin (RIF) and isoniazid (INH), becomes a crucial factor for the control of the disease, since patients harboring MDR strains of MTb need to be entered into alternative management schedules involving second-line drugs [1-4]. MDR-TB greatly complicates patient management especially within resource-poor national TB programs, by reducing effectiveness of the treatment regime while increasing the cost.

The TB profile of Sri Lanka on World Health Organization (WHO) reports, that in 2016 MDR rate in Sri Lanka was $0.54 \%$ among newly diagnosed cases and

(c) The Author(s). 2019 Open Access This article is distributed under the terms of the Creative Commons Attribution 4.0 International License (http://creativecommons.org/licenses/by/4.0/), which permits unrestricted use, distribution, and reproduction in any medium, provided you give appropriate credit to the original author(s) and the source, provide a link to the Creative Commons license, and indicate if changes were made. The Creative Commons Public Domain Dedication waiver (http://creativecommons.org/publicdomain/zero/1.0/) applies to the data made available in this article, unless otherwise stated. 
$3.1 \%$ among retreatment cases, with 23 laboratory confirmed MDR TB cases and an estimated TB incidence remaining stable at 65 new cases per 100000 population [5]. Irrespective of this incidence rate, early diagnosis of MDR TB is essential to control the spread of the disease to reach the goals of the End TB strategy [2].

The phenotypic methods based on conventional cultures that detect growth of MTb in the presence of a particular antibiotic are time consuming. Thus, modern molecular detection methods have been developed for the rapid identification of INH and RIF resistance as well as MTb. An allele-specific PCR targeting katG 315 gene and an inhA $\mathrm{C}-15 \mathrm{~T}$ mutation in the regulatory region of the mabA-inhA operon to detect INH-resistant MTb strains and to identify the Mycobacterium tuberculosis Complex (MTC) in the same PCR tube [6] is a successful method reported recently. Detection of MDR using lateral flow nucleic acid biosensors focusing katG315 and rpoB531 common mutations [7] and detection of RIF resistance using magnetic nanobead based read out [8] are two other recently reported molecular methods based on padlock probes for determination of drug resistance. An assay based on AuNP to differentiate MTb from MTC using clinical specimens was developed by Soo and co-workers in 2009 [9].

The two line-probe assays for $\mathrm{TB}$, namely the INNO-LiPA Rif.TB assay (Innogenetics NV, Ghent, Belgium) [10-14] and the GenoType MTBDR plus (Hain Lifescience GmbH, Nehren, Germany) $[14,15]$ have been custom-made to detect mutations causing RIF and INH drug resistance with satisfactory sensitivity and specificity $[16,17]$. But it is known that the sensitivity of these tests is lower for INH compared to RIF [18]. In recent times an automated cartridgebased technology (GeneXpert MTB/RIF, Cepheid Inc.) has been introduced for simultaneous detection of MTb and RIF resistance directly from sputum as well as extra pulmonary samples $[19,20]$. One obvious disadvantage is the inability of this system to detect INH resistance.

However, the availability of these molecular detection methods is very limited in Sri Lanka as the commercial systems are costly in terms of infrastructure and equipment. Therefore, this study was aimed at developing a simple, convenient and rapid AuNP based lateral flow strip for the simultaneous detection of most common INH resistance mutation (katG S315 T) and MTb.

\section{Methods}

\section{Sample collection}

Acid Fast Bacilli (AFB) positive sputum specimens $(n=$ 541) were collected from the Central Chest Clinic, Colombo from 2013 to 2016. The sputum specimens were processed and cultured on Lowenstein Jensen medium to isolate MTb strains. A total of 450 cultures were confirmed as MTb using phenotypical characters (growth rate, color and colony morphology) and PCR amplification of IS6110 insertion element of the MTb genome. Fifteen (15) INH resistant isolates were identified among the 450 isolates by the agar proportion method. In addition, $41 \mathrm{INH}$ resistant MTb strains isolated from sputum samples received from chest clinics were directly collected from National Tuberculosis Reference Laboratory (NTRL), Welisara, Sri Lanka.

\section{DNA extraction and multiplex PCR amplification}

Genomic DNA of INH resistant MTb isolates was extracted using phenol-chloroform method [21]. The extracted DNA was quantified by agarose gel electrophoresis (1.5\%) using lambda DNA (539 ng/ $\mu \mathrm{l}$, Promega).

Multiplex PCR was performed using two specific primer sets to amplify a $217 \mathrm{bp}$ fragment of katG gene flanking the codon 315 and a $249 \mathrm{bp}$ fragment of IS6110 insertion region specific to MTC for identification of INH resistance and MTb [22] simultaneously (Table 1). MTC consists of seven Mycobacterium species including MTb, M. africanum, M. bovis, M. microti, M. canetti, $M$. caprae and M. pinnipedii.

The H37Rv reference MTb strain and a known INH resistant MTb strain confirmed by the NTRL, Welisara, Sri Lanka were used as quality control strains.

\section{Designing of probes}

The AuNP based lateral flow assay requires two types of probes; detection probes conjugated to AuNP and biotin labeled capture probes. In this study two detection probes and four capture probes were designed.

Detection probe katG (DP katG): Oligonucleotide sequence which is complementary to the $5^{\prime}$ end of the amplified DNA fragment (target) of katG gene.

Detection probe for TB (DP TBD): Oligonucleotide sequence which is complementary to the $5^{\prime}$ end of the amplified DNA fragment of IS6110 insertion region.

Capture probe for wild type and the mutated strains detection (CP WT and CP ACC): Oligonucleotide sequence which is complementary to the $3^{\prime}$ end of the target amplified DNA fragment of katG gene. These two probes were designed focusing the codon 315 position where the most common point mutation occurs.

Capture probe for TB detection (CP TBD): Oligonucleotide sequence which is complementary to the $3^{\prime}$ end of the target amplified DNA fragment of MTb specific region.

Capture probe for control (CP Control): Oligonucleotide sequence complementary to the DP TBD 
Table 1 Primers and reaction conditions used for the multiplex PCR amplification of TB specific region and the katG 315 region

\begin{tabular}{|c|c|c|c|c|}
\hline $\begin{array}{l}\text { Multiplex } \\
\text { PCR primer }\end{array}$ & Sequence (5' to 3') & $\begin{array}{l}\text { Amplified } \\
\text { fragment }\end{array}$ & $\begin{array}{l}\text { Product } \\
\text { size (bp) }\end{array}$ & PCR conditions \\
\hline $\begin{array}{l}\text { Pt18 } \\
\text { INS2 }\end{array}$ & $\begin{array}{l}\text { GAACCGTGAGGGCATCGAGG } \\
\text { GCGTAGGCGTCGGTGACAAA }\end{array}$ & $\begin{array}{l}\text { IS6110 } \\
\text { region }\end{array}$ & 249 & \multirow{2}{*}{ 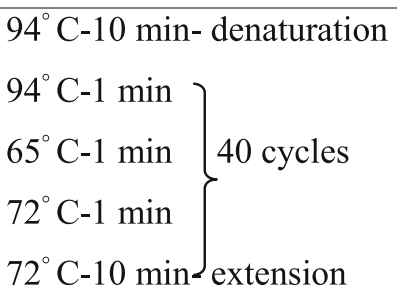 } \\
\hline $\begin{array}{l}\text { kat } G \text { forward } \\
\text { kat } G \text { reverse }\end{array}$ & $\begin{array}{l}\text { GTC GGC GGT CAC ACT TTC } \\
\text { AGC CGT ACA GGA TCT CGA GG }\end{array}$ & $\begin{array}{l}\text { katG315 } \\
\text { region }\end{array}$ & 217 & \\
\hline
\end{tabular}

detection probe. Hybridization of DP TBD to the CP control will verify the assay performance.

These probes were designed using IDT Oligo Analyzer 3.1 tool to contain a poly A tag and thiol or biotin modifications as described in previous procedures $[9,23,24]$ (Table 2). The poly A tag was introduced to the $5^{\prime}$ end of the detection probes and to the 3' end of each of the capture probes. Detection probes were thiol-modified and conjugated with AuNPs under optimized conditions. Thiol modification facilitated the stronger binding of AuNP to the detection probe via the formation of strong Au-S bonds $[7,8]$. Capture probes were labeled with biotin for the easy conjugation with streptavidin.

\section{Synthesis, purification, and characterization of gold nanoparticles}

AuNPs were prepared according to the previously described citrate method [23, 25]. First, all glassware were thoroughly cleaned with aqua regia (three parts conc. $\mathrm{HCl}$, one part conc. $\mathrm{HNO}_{3}$ ), rinsed with copious amounts of water followed by nanopure water, and oven-dried prior to use. In a $500 \mathrm{~mL}$ roundbottom flask, $200 \mathrm{~mL}$ of $1 \mathrm{mM} \mathrm{HAuCl}_{4}$ prepared in nanopure water was brought to a boil with vigorous stirring under continuous condensation. To this solution, $4 \mathrm{~mL}$ of $39 \mathrm{mM}$ trisodium citrate was added. The solution turned deep blue within $20 \mathrm{~s}$, and finally the color changed to wine-red few minutes later indicating the formation of AuNPs. Boiling was continued for an additional $10 \mathrm{~min}$ to ensure complete reaction and the colloid solution was then stirred for further $15 \mathrm{~min}$ while allowing it to cool to room temperature. The resulting AuNP suspension was aliquoted into $2 \mathrm{~mL}$ volumes and centrifuged at 6000 $\mathrm{rpm}$ for $1 \mathrm{~h}$ to remove any unreacted material from the supernatant. The separated AuNP pellet was then diluted using a $0.5 \mathrm{mM}$ citrate storage buffer back to the initial volume $(2 \mathrm{~mL})$ and the AuNPs were redispersed in solution followed by the centrifugation at $6000 \mathrm{rpm}$ for another $1 \mathrm{~h}$. This step was repeated for 3 times to ensure the complete removal of unreacted materials in the as-synthesized media and hence increased the stability of AuNPs. Localized Surface Plasmon Resonance spectrum (LSPR) of purified Au-NPs indicated a $\lambda_{\max }$ of $523 \mathrm{~nm}$ [7] as shown in Fig. 1 (A). According to the approach previously developed by Haiss and co-workers [26], this LSPR behavior evidenced the presence of gold nanoparticles of $\sim 20 \mathrm{~nm}$ average diameter, at a $\sim 2.5 \mathrm{nM}$ particle concentration. Further, the narrow spectral bandwidth and the absence of any secondary spectral features in the LSPR spectrum of the synthesized AuNP, subsequent to purification, indicated good homogeneity in particle size and appreciable stability under the experimental conditions. Additionally, high resolution transmission electron microscopic (HRTEM - JEOL JEM 2100) images of the prepared AuNPs were obtained to

Table 2 Oligonucleotides used in the development of the assay

\begin{tabular}{lll}
\hline Probe name & Description & Sequence (5' to 3') with modification $^{\prime}$ \\
\hline CP WT & Wild type probe (strip oligo) & GATCACCAGCGGCATCGAGAAAAAAAAAA -Biotin \\
CP ACC & Mutation probe (strip oligo) & GATCACCACCGGCATCGAGAAAAAAAAAA -Biotin \\
CP TBD & TB detection probe (strip oligo) & GGC TGT GGG TAG CAG ACC AAAAAAAAAA -Biotin \\
CP Control & Control probe (strip oligo) & CCGTCGACGGT GCA TCT G AAAAAAAAA -Biotin \\
DP TBD & TB detection probe (with AuNP) & HS-AAAAAAAAAACAGATGCACCGTCGAACGG \\
DP katG & katG detection probe (with AuNP) & HS-AAAAAAAAAAGCTGGAGCA GATGGGCTT \\
\hline
\end{tabular}



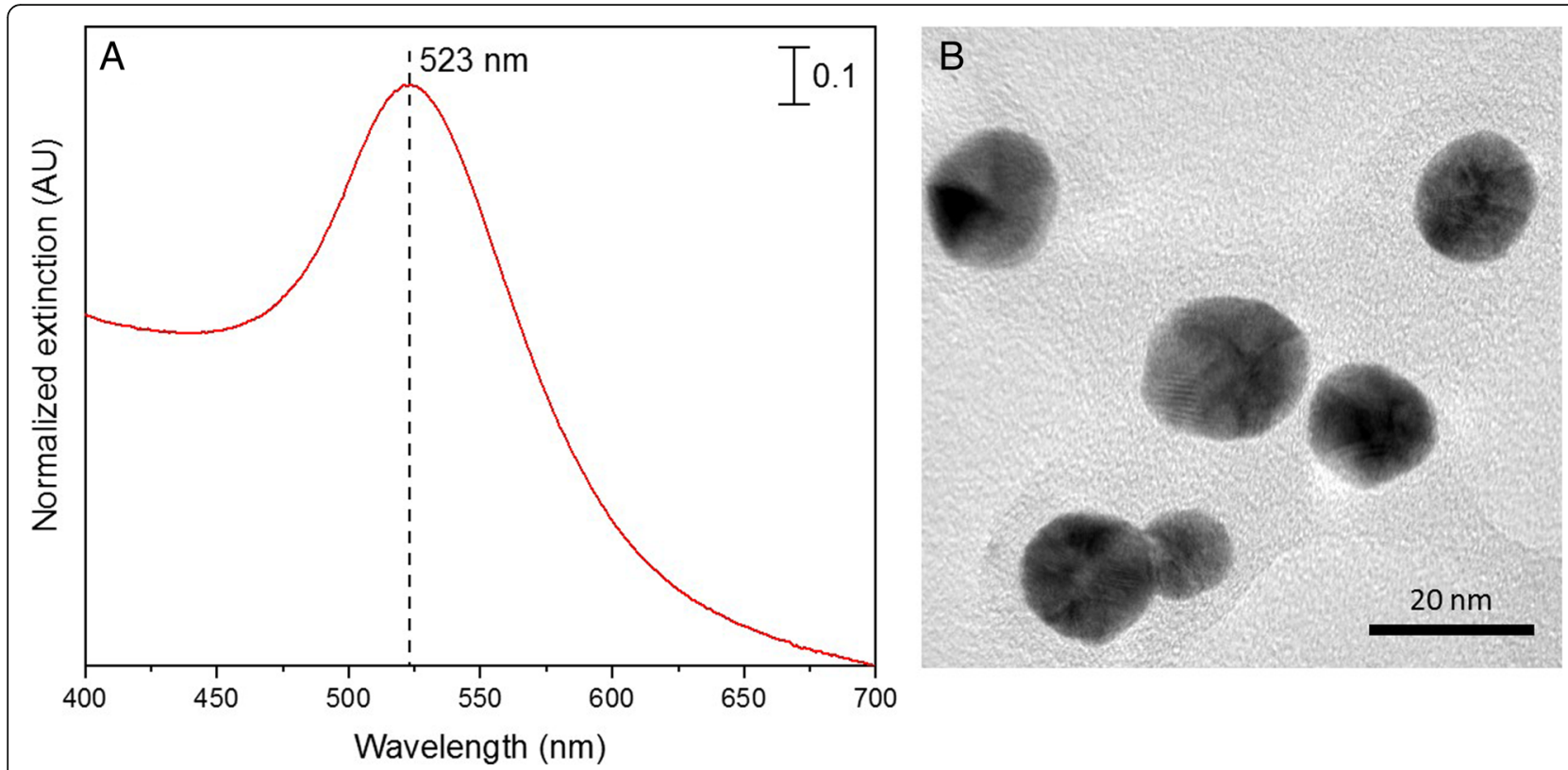

Fig. 1 (a) Localized Surface Plasmon Resonance (LSPR) spectrum and (b) a representative HRTEM image of gold nanoparticles

reconfirm the size of the AuNPs as shown in the representative HRTEM micrograph image given in Fig. 1 (B). The HRTEM indicated the presence of spherical and monodisperse gold nanoparticles of $\sim 20 \mathrm{~nm}$ diameter, reconfirming the inference made via the LSPR spectrum. Importantly, these particles were very stable in solution and no changes could be observed in the LSPR spectra even after several weeks postsynthesis. Hence, the AuNPs were stored at $4{ }^{\circ} \mathrm{C}$ until they were utilized in the conjugation procedure.

\section{Conjugation of AuNPs to detection probes}

The preparation of DNA conjugated AuNPs was modified from the procedure previously described [24]. First, $20 \mu \mathrm{L}$ of $100 \mu \mathrm{M}$ thiol-modified oligonucleotides were gently added to $500 \mu \mathrm{L}$ of colloidal gold. The solution was incubated at $4{ }^{\circ} \mathrm{C}$ in the dark conditions for $24 \mathrm{~h}$. Then the solution was added to $10 \mathrm{mM}$ phosphate buffer $(\mathrm{pH}=7)$. A $30 \mu \mathrm{L}$ volume of $1 \mathrm{M} \mathrm{NaCl}$ solution was added drop wise to the solution and centrifuged at $12000 \mathrm{rpm}$ for $20 \mathrm{~min}$. The resulting conjugated AuNPs were blocked in $500 \mu \mathrm{L}$ of $5 \%$ Bovine Serum Albumin (BSA) solution for 30 min at $25^{\circ} \mathrm{C}$ followed by $12000 \mathrm{rpm}$ centrifugation for $15 \mathrm{~min}$. The final colloid sample was re-dispersed in $500 \mu \mathrm{L}$ of sample eluent buffer (10\% sucrose, $20 \mathrm{mM}$ $\mathrm{Na}_{3} \mathrm{PO}_{4}, 5 \%$ BSA, $0.25 \%$ Tween 20) [23]. The addition of BSA, tween 20 and sucrose facilitates the stability of AuNPs. Conformation of the conjugation of AuNPs to detection probes was done using spectrophotometric analysis $[7,8]$. A shift of LSPR $\lambda_{\max }$ from $523 \mathrm{~nm}$ to $526 \mathrm{~nm}$ showed that the prepared AuNPs were conjugated with the oligonucleotides.

\section{Conjugation of streptavidin to capture probes}

Conjugation of streptavidin to biotin labeled capture probes was done using the previously described procedure [23] with slight modifications. Briefly, $1 \mathrm{mg}$ of streptavidin was dissolved in $900 \mu \mathrm{L}$ of $1 \mathrm{x}$ PBS. A $220 \mu \mathrm{L}$ volume of this solution was mixed with $20 \mu \mathrm{L}$ of $1 \mathrm{mM}$ capture probe in a microcentrifuge tube and incubated $1 \mathrm{~h}$ at $25^{\circ} \mathrm{C}$ and $1 \mathrm{~h}$ at $37^{\circ} \mathrm{C}$. Excess probes were removed by 30,000 cut off centrifugal filter (Millipore) by centrifugation at $6000 \mathrm{rpm}$. Resulted conjugates were washed with $300 \mu \mathrm{L}$ of $1 \mathrm{x}$ PBS two times in the same centrifugal filter. Remaining solution of the filter was eluted into a new microcentrifuge tube and stored at $4{ }^{\circ} \mathrm{C}$.

\section{Lateral flow strip preparation}

Lateral flow strip was designed to contain a sample pad, test zone and an absorption pad mounted on an inert plastic backing layer. The test zone includes separate test lines for mutation probe, wild type probe, MTb identification probe and the control probe (Fig. 2). The sample pad was prepared by saturating a cellulose pad with $100 \mu \mathrm{L}$ of sample pad saturation buffer $(0.25 \%$ Triton X100, $0.05 \mathrm{M}$ Tris $\mathrm{HCl}$, $0.15 \mathrm{M} \mathrm{NaCl}, \mathrm{pH}=8$ ) [23]. It was dried and stored in a dessicator. Absorption pad was also a cellulose pad which was used to facilitate the flow of solutions throughout the strip via capillary action. Test zone on 


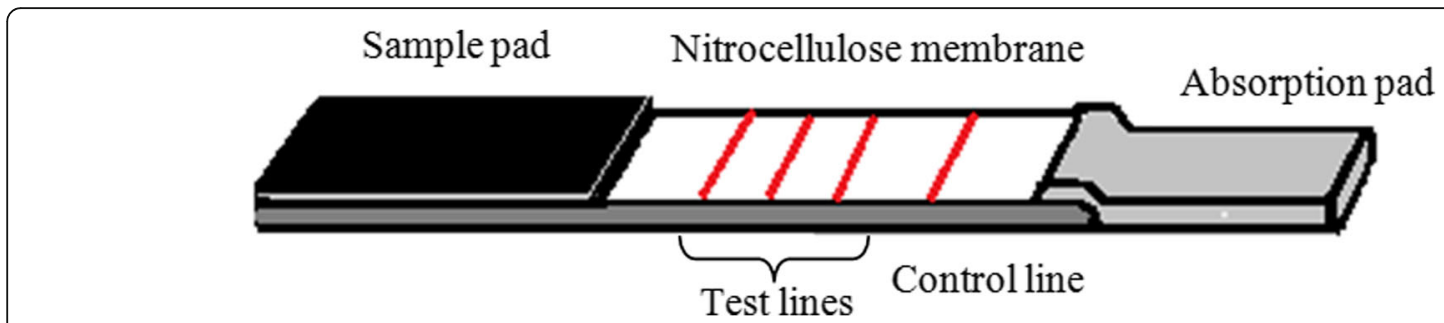

Fig. 2 Schematic illustration of the lateral flow strip

the nitrocellulose membrane was used to immobilise the streptavidine conjugated biotin labelled capture probes as test lines and a control line. A $0.6 \mu \mathrm{L}$ volume of each streptavidin conjugated capture probe was spotted as a line using a micro pipette and the membrane was incubated $16 \mathrm{~h}$ at $37^{\circ} \mathrm{C}$. The nitrocellulose membrane was blocked with $50 \mu \mathrm{L}$ of membrane blocking buffer (1\% sucrose, 1\% BSA, $2.5 \%$ Tween 20, $0.1 \mathrm{M} \mathrm{NaH} \mathrm{PO}_{4}$ ) and incubated at $37^{\circ} \mathrm{C}$ for $30 \mathrm{~min}$. The sample pad, nitrocellulose membrane and the absorption pad were assembled on a plastic backing layer to form the lateral flow strip (Fig. 2).

\section{Assay procedure}

A $5 \mu \mathrm{L}$ volume of multiplex PCR amplified product was denatured at $99^{\circ} \mathrm{C}$ for $8 \mathrm{~min}$ and immediately cooled in ice for $5 \mathrm{~min}$. Then, $10 \mu \mathrm{L}$ of each of the TB detection and $k a t G$ detection probes were mixed with the PCR amplified, denatured targets (katG gene fragment and IS6110 insertion region fragment) and hybridized at $42{ }^{\circ} \mathrm{C}$ for $15 \mathrm{~min}$ in a microcentrifuge tube. The resulting hybridized mixture was introduced on to the sample pad followed by the addition of $40 \mu \mathrm{L}$ of running buffer (1\% BSA, $0.2 \%$ tween $20,0.01 \%$ SDS in $6 x$ SSC) [23]. The capture probes on the strip were then allowed to hybridize to the above mixture at $48^{\circ} \mathrm{C}$ for $15 \mathrm{~min}$ and were washed with $4 \mathrm{x}$ SSC buffer.

\section{Limit of detection}

Concentration of the extracted target genomic DNA was determined using Quantus fluorometer (Promega). Twofold serial dilution was done for the target DNA starting with $32 \mathrm{pg} / \mu \mathrm{L}$ (H37Rv strain) and $50 \mathrm{pg} / \mu \mathrm{L}$ (INH resistant reference strain). Thereafter, multiplex PCR was carried out for all dilutions (five dilutions of each strain). The resulted multiplex PCR products were denatured and subjected to the above assay procedure. The strips were prepared individually for each capture probe (TBD, WT and ACC) along with the control probe. The multiplex PCR products of $\mathrm{H} 37 \mathrm{Rv}$ strain was used to determine the limit of detection (LOD) of TBD and WT capture probes while PCR product of the reference mutant strain was used to determine the LOD of ACC capture probe.

\section{Validation of the assay}

First, specificity of the assay was performed using DNA of five different species of non-tuberculous mycobacteria (NTM) (M. abscessus, M. fortuitum, M. avium, M. smegmatis, M. kansasii). These five isolates are used as the reference NTM standards in the laboratory and have been confirmed as NTM by biochemical testing and DNA sequencing.

Then, the assay was evaluated as a molecular method for simultaneous identification of both TB and INH resistance. The mutant probe was validated using $38 \mathrm{INH}$ resistant MTb isolates which were prior confirmed using agar proportion method followed by DNA sequencing. Wild type probe was validated using $20 \mathrm{INH}$ susceptible isolates confirmed by agar proportion method. The validation of the TB detection probe was carried out using all $58 \mathrm{MTb}$ isolates. They were confirmed as MTb by PCR amplification of the $240 \mathrm{bp}$ fragment of the IS6110 element.

The specificity of the TB detection probe was determined using 10 NTM isolates (other than the 5 isolates mentioned above). These NTM isolates produced negative results for IS6110 fragment PCR amplification confirming absence of MTb. Specificity of the mutant probe and wild type probe was determined using the above 20 INH susceptible isolates and $38 \mathrm{INH}$ resistant isolates respectively [14]. The $\mathrm{H} 37 \mathrm{Rv}$ reference $\mathrm{MTb}$ strain as well as the confirmed INH resistant isolate by NTRL was used as the controls.

Sensitivity and the specificity of each of the three probes were statistically calculated using SPSS 18 software.

\section{Results and discussion}

The lateral flow assay done using the reference and test isolates are shown in Fig. 3 (3A and 3B respectively). The control line appeared within $\sim 20 \mathrm{~min}$ and the test lines became visible in $\sim 35 \mathrm{~min}$. Thus the total assay time is approximately $35 \mathrm{~min}$.

In the assay procedure, both detection probes (DP katG and DP TBD conjugated to AuNPs) were hybridized to $5^{\prime}$ end of the each of the two mobile target DNA fragments in a microcentrifuge tube. The 3' end of the mobile target DNA (carrying the detection probes) would then hybridize to the immobilized 

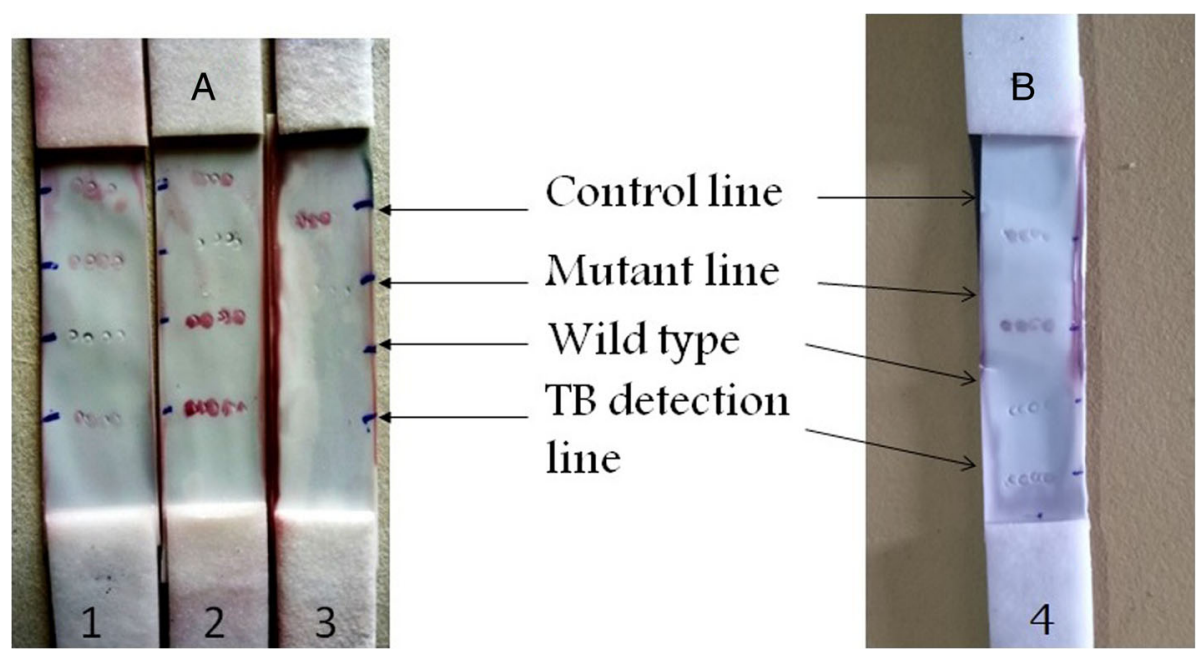

Fig. 3 Lateral flow assay strip run with DNA of reference INH resistant isolate (A1), wild type H37Rv (A2), NTM isolate (A3) and INH resistant test isolate (B4)

capture probes on the nitrocellulose membrane resulting in a red color at the relevant test line due to the accumulation of AuNPs conjugated to detection probes (Fig. 4). The excess TBD detection probe that flows through the nitrocellulose membrane will then hybridize with the complementary control capture probe. A positive signal at the control line confirms the correct direction of the flow.

The Table 3 shows the LOD of each of the capture probes individually using reference $\mathrm{H} 37 \mathrm{Rv}$ strain and the INH resistant mutant strain. The PCR product of the lowest DNA concentration that produced an intense red colour band was recorded as the LOD of each of the probe. However, LOD for the overall assay was taken as $6.25 \mathrm{pg} / \mu \mathrm{L}$ (LOD of $\mathrm{CP}$ ACC) since all probes were immobilized on a single strip.

When the specificity of the assay performed using DNA of reference NTM species (M. abscessus, $M$. fortuitum, $M$. avium, M. smegmatis, $M$. kansasii), all five NTM species showed a positive band only for the control line confirming $100 \%$ specificity.

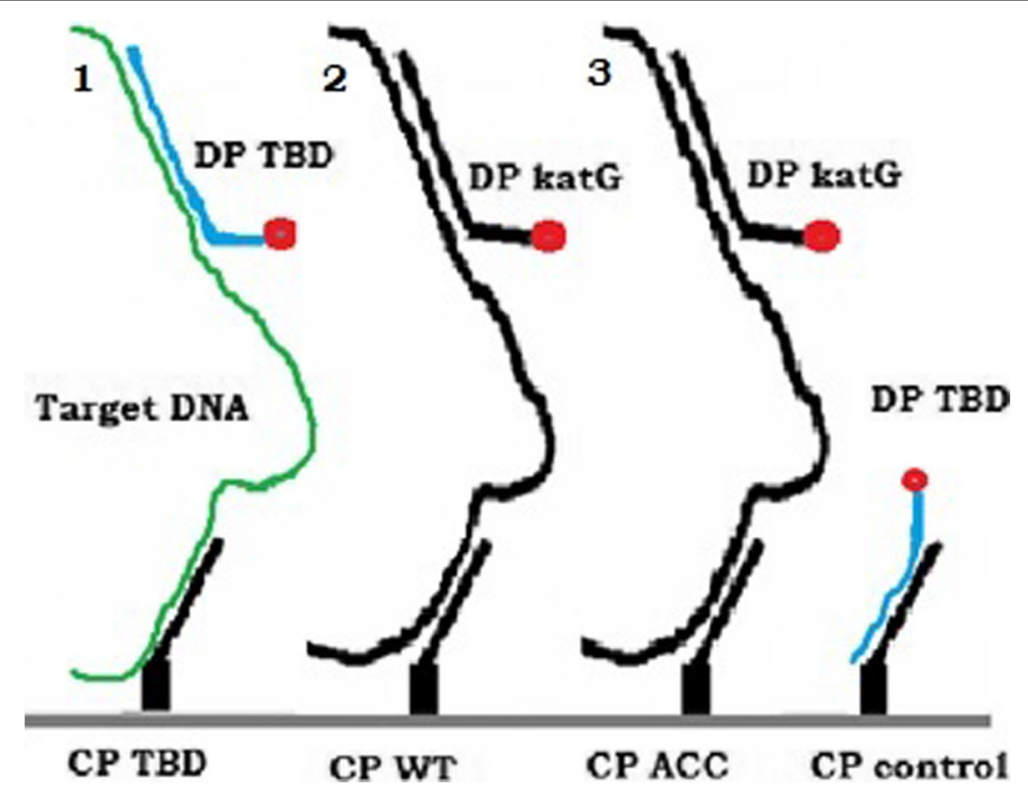

Fig. 4 Schematic illustration of the lateral flow assay (DP- detection probe, CP-capture probe, TBD- Tb detection, katG - kat G detection, WT-wild type katG, ACC-mutant katG,1- IS 6110 PCR fragment, 2 \& 3- katG gene PCR fragments) 
Table 3 Limit of detection of each capture probe

\begin{tabular}{llll}
\hline DNA of the isolate & CP TBD & CP WT & CP ACC \\
\hline H37Rv & $2 \mathrm{pg} / \mu \mathrm{L}$ & $4 \mathrm{pg} / \mu \mathrm{L}$ & - \\
Reference mutant strain & $3.125 \mathrm{pg} / \mu \mathrm{L}$ & - & $6.25 \mathrm{pg} / \mu \mathrm{L}$ \\
\hline
\end{tabular}

The details of the evaluation of the performance of assay as a molecular method for simultaneous identification of both TB and INH resistance is shown in Table 4.

With the lateral flow assay out of the 68 isolates, 65 isolates revealed expected results providing 96.6\% compatibility. Three isolates gave false negative results for the detection by the mutant probe. Of these three isolates two isolates were also negative for the TB detection probe (Table 4).

Sensitivity and the specificity of the assay for each of the three capture probes are shown in Table 5.

In the optimization process of the assay, the hybridization temperature of each probe was initially determined. Thereafter, the hybridization temperature for the strip was optimized to a single temperature since all probes were immobilized on the same strip. Flushing 4x SSC buffer over the strip as a washing process facilitated the specific binding of each of the probe. A clear background was obtained when freshly prepared membrane blocking buffer was used after immobilization of the capture probes on to the nitrocellulose membrane. The components in the sample pad saturation buffer would facilitate the flow of DNA conjugates towards the adsorption pad by reducing entrapment of target DNA conjugates in the sample pad.

Most lateral flow strips contain a conjugate pad saturated with the AuNPs conjugated detection probes, which is placed in between the sample pad and the nitrocellulose membrane $[23,27,28]$. But, in the current method, the hybridization of target DNA sample with the AuNPs conjugated detection probes was done in a separate micro-centrifuge tube to achieve maximum hybridization between the target and the AuNPs conjugate. Since this hybridized solution was applied on to the sample pad of the strip, it facilitated the hybridization with immobilized capture probes enhancing the color intensity of the bands. In the current assay, a cellulose pad was used as the sample pad instead of a glass fiber pad to reduce the cost.

The maximum storage time of the developed strip was 2 weeks in a desiccator at room temperature $\left(25^{\circ} \mathrm{C}\right)$, but use of a clamshell laminator to assemble the strip on the plastic backing layer will be a more efficient way to increase the expiry date. Additionally, it will shorten the time required for manual preparation of assay strips. The manual dispensing of the capture probes as spots in a line using a micropipette on the nitro cellulose membrane was time consuming and laborious. Use of air jet dispensers will be a more efficient method and it will minimize the amount of capture probes required per strip.

Even though, the strip was developed manually using minimum resources which were available in the laboratory, it was adequate to discriminate between mutant and wild types efficiently. A few INH resistant isolates $(n=4)$, gave a very weak positive wild type line along with the intense mutant line. This was acceptable because some of the pure MTb cultures could contain a mixture of both mutated and wild type strains [29].

Although the TB detection conjugate probe was validated using MTb isolates, any one of the seven Mycobacterium species of MTC can be detected by the strip since the TB detection capture probe was designed based on gene sequence in IS6110 insertion element common to MTC.

This assay was developed for the detection of the most common katG315 (AGC to ACC) mutation (78.6\%) [30] responsible for INH resistance in Sri Lanka. But the strip can be further developed to detect other less common INH resistant mutations (AGC to AAC/AGA) in Sri Lanka by immobilizing the relevant mutation specific capture probes on to the strip, so that custom made strips can be prepared depending on the frequency and types of mutations in a particular geographical setting. Furthermore, the strip can be developed to detect MDR TB by introducing a specific probe to detect RIF resistance using

Table 4 Validation of the assay strip using INH resistant, susceptible and NTM isolates

\begin{tabular}{|c|c|c|c|c|c|c|}
\hline \multirow[t]{2}{*}{ Isolates } & \multicolumn{2}{|c|}{ Mutant probe (CP ACC) } & \multicolumn{2}{|c|}{ WT probe (CP WT) } & \multicolumn{2}{|c|}{ TB detection probe (CP TBD) } \\
\hline & $P$ & $N$ & $P$ & $N$ & $P$ & N \\
\hline INH resistant $(n=38)$ & 35 & 3 & 0 & 38 & 36 & 2 \\
\hline INH susceptible $(n=20)$ & 0 & 20 & 20 & 0 & 20 & 0 \\
\hline NTM $(n=10)$ & 0 & 10 & 0 & 10 & 0 & 10 \\
\hline False positive & - & & - & & - & \\
\hline False negative & $3(4.4 \%)$ & & - & & $2(2.9 \%)$ & \\
\hline
\end{tabular}


Table 5 Sensitivity and specificity of the three capture probes

\begin{tabular}{lllll}
\hline Probe & Specificity (\%) & Sensitivity (\%) & Positive predictive value (\%) & Negative predictive value (\%) \\
\hline Mutant probe (CP ACC) & 100.0 (C.I. 84.6-100.0) & 92.1 (C.I. 84.0-92.1) & 100.0 (C.I. 90-100) & 87.0 (C.I. 66.4-97.2) \\
Wild type probe (CP WT) & 100.0 (C.I. 93.1-100.0) & 100.0 (C.I. 86.8-100.0) & 100.0 (C.I. 86.8-100) & 100.0 (C.I. 93.1-100.0) \\
TB detection probe (CP TBD) & 100.0 (C.I. 71.9-100.0) & 96.6 (C.I. 91.7-96.6) & 100.0 (C.I. 93.1-100) & 83.3 (C.I. 51.6-98.0) \\
\hline
\end{tabular}

most common rpoB526 mutation (CAC to TAC) reported in Sri Lanka [31].

\section{Conclusion}

This AuNP based lateral flow assay is appropriate for INH resistance screening in low resource settings as it reliably differentiates the resistant mutation from the wild type simultaneously with MTb identification within $3 \mathrm{~h}$ time beside its convenient use.

\section{Abbreviations \\ AuNP: gold nanoparticle; BSA: Bovine Serum Albumin; CP ACC: Capture probe for mutated katG315; CP Control: Capture probe for control; CP TBD: Capture probe for TB detection; CP WT : Capture probe for wild type katG315; DP katG: Detection probe katG; DP TBD: Detection probe for TB; HRTEM: High resolution transmission electron microscope; INH: Isoniazid; LOD: Limit of detection; LSPR: Localized Surface Plasmon Resonance spectrum; MDR : multidrug-resistant; MTb: Mycobacterium tuberculosis; MTC: Mycobacterium tuberculosis complex; NTM: Non-tuberculous mycobacteria; NTRL: National Tuberculosis Reference Laboratory; PCR: Polymerase chain reaction; RIF: Rifampicin; TB: tuberculosis}

\section{Acknowledgements}

The authors thank Dr. Channa Senanayake and the staff of Department of Microbiology, Faculty of Medicine, Dr. N.V Chandrasekharan, Department of Chemistry, University of Colombo, Dr. Dhammika Vidanagama and the laboratory staff of National Tuberculosis Reference Laboratory, Welisara, Damayanthi Dahanayaka, SLINTEC, Homagama and Dr. Ananda Wijayasiri for providing assistance.

\section{Authors' contributions}

REK, AJP, WSSW and CPA designed the study; AJP, WSSW and CPA supervised the work of REK. REK carried out the laboratory work and analyzed the data; LW and REK carried out the AuNP synthesis and characterization; REK, AJP, WSSW, CPA, LW and NDS interpreted the data. REK drafted the manuscript. AJP, WSSW, CPA, LW and NDS revised the manuscript. All authors read and approved the final manuscript.

\section{Funding}

The study was financially supported by the National Research Council, Sri Lanka (Grant No: NRC 12-140) and did not contribute to the study design development, specimen collection, analysis, and interpretation of data and in writing the manuscript.

\section{Availability of data and materials}

The datasets used and/or analyzed during the current study are available from the corresponding author on reasonable request.

\section{Ethics approval and consent to participate}

The study was approved by the Ethics Review Committee of the Faculty of Medicine, University of Colombo, Sri Lanka (EC/06/062).

\section{Consent for publication}

Not applicable.

\section{Competing interests}

The authors declare that they have no competing interests.

\section{Author details}

'Department of Microbiology, Faculty of Medicine, University of Colombo, box 271, Kynsey Road, Colombo, PO 08, Sri Lanka. ${ }^{2}$ Sri Lanka Institute of Nanotechnology (SLINTEC), Mahenwatte, Pitipana, Homagama, Sri Lanka. ${ }^{3}$ Department of Chemistry, Faculty of Natural Sciences, The Open University of Sri Lanka, Nawala, Sri Lanka. ${ }^{4}$ Department of Molecular Biology and Biochemistry, Faculty of Medicine, University of Colombo, Colombo 08, Sri Lanka. ${ }^{5}$ Department of Chemistry, University of Colombo, Colombo 03, Sri Lanka. ${ }^{6}$ Central Public Health Laboratories, National Tuberculosis Reference Laboratory, Ministry of Health, Muscat, Sultanate of Oman.

Received: 12 November 2018 Accepted: 4 July 2019

Published online: 12 July 2019

\section{References}

1. Wright A, Tomlinson G S, Rangaka M X and Fletcher H A. World TB Day 2018: The Challenge of Drug Resistant Tuberculosis, F1000 Research 2018; 7: 217 doi: 10.12688/ f1000research.14088.1.

2. Global tuberculosis report 2017. Geneva: World Health Organization; 2017. Licence: CC BY-NCSA 3.0 IGO.

3. Chiang CY, Centis R, Migliori GB. Drug-resistant tuberculosis: Past, present, future. Respirology. 2010;15:413-32.

4. Zager E. M and McNerney R. Multidrug-resistant tuberculosis, BMC Infect Dis, 2008; 8:10 doi:10.1186 /1471-2334-8-10.

5. Global tuberculosis report 2016. Geneva: World Health Organization; 2016. Licence: CC BY-NCSA 3.0 IGO.

6. Herrera-León L, Molina T, Saíz P, Sáez-Nieto JA, Jiménez MS. New multiplex $P C R$ for rapid detection of isoniazid-resistant Mycobacterium tuberculosis clinical isolates. Antimicrob Agents Chemother. 2005;49(1):144-7.

7. Pavankumar AR, Engström A, Liu J, Herthnek D, Nilsson M. Proficient detection of multi-drug-resistant Mycobacterium tuberculosis by padlock probes and lateral flow nucleic acid biosensors. Anal Chem. 2016;88(8): 4277-84. https://doi.org/10.1021/acs.analchem.5b04312.

8. Engstrom A., Zardan Gomez de la Torre T., Strømme M., Nilsson M., Herthnek D. Detection of Rifampicin Resistance in Mycobacterium tuberculosis by Padlock Probes and Magnetic Nanobead-Based Readout. PLoS ONE 2013; 8(4): e62015. doi:https://doi.org/10.1371/journal.pone. 0062015

9. Soo P, Horng Y, Chang K, Wang J, Hsueh P, Chuang C, Lu C, Lai H. A simple gold nanoparticle probes assay for identification of Mycobacterium tuberculosis and Mycobacterium tuberculosis complex from clinical specimens. Mol Cell Probes. 2009:23:240-6.

10. Rossau R., Traore H., De Beenhouwer H., Woute, evaluation of the INNO-LiPA Rif. TB Assay, a Reverse Hybridization Assay for the Simultaneous Detection of Mycobacterium tuberculosis Complex and Its Resistance to Rifampin , Antimicrob Agents Chemother, 1997; 41(10): 2093-2098.

11. Rufai SB, Kumar P, Singh A, Prajapati S, Balooni V, Singh S. Comparison of Xpert MTB/RIF with line probe assay for detection of rifampin-Monoresistant Mycobacterium tuberculosis. J Clin Microbiol. 2014;52(6):1846-52.

12. Tortoli E, Marcelli F. Use of the INNO LiPA Rif.TB for detection of Mycobacterium tuberculosis DNA directly in clinical specimens and for simultaneous determination of rifampin susceptibility. Eur J Clin Microbiol Infect Dis 2007 Jan;26 (1):51-55. PubMed PMID: 17180347

13. Viveiros $M$, Leandro $C$, Rodrigues $L$, et al. Direct application of the INNOLiPA Rif.TB line-probe assay for rapid identification of Mycobacterium tuberculosis complex strains and detection of rifampin resistance in 360 smear-positive respiratory specimens from an area of high incidence of multidrug-resistant tuberculosis. J Clin Microbiol. 2005:43(9):4880-4.

14. European Centre for Disease Prevention and Control. ERLN-TB expert opinion on the use of the rapid molecular assays for the diagnosis of tuberculosis and detection of drug-resistance. Stockholm: ECDC; 2013. 
Stockholm, July 2013 ISBN 978-92-9193-483-6 doi https://doi.org/10.2900/ 8592 Catalogue number TQ-02-13-155-EN-C

15. Bai, Y., Wang, Y., Shao, C., Hao, Y., Jin, Y. X GenoType MTBDRplus Assay for Rapid Detection of Multidrug Resistance in Mycobacterium tuberculosis: A Meta-Analysis. PLOS ONE 2012; 11(3): e0150321. https://doi.org/10.1371/ journal.pone.0150321.

16. Lacoma, A., Garcia-Sierra, N., Prat, C., Ruiz-Manzano, J., Haba, L., Rose's, s., Maldonado, J. and Domínguez J.x GenoType MTBDRplus assay for molecular detection of rifampin and isoniazid resistance in Mycobacterium tuberculosis strains and clinical samples, J Clin Microbiol, 2016; Vol. 46, No. 11: 3660-3667, doi:https://doi.org/10.1128/JCM.00618-08.

17. Wang, S., Inci, F., De Libero, G., Singha,A. and Demirci,U.. Point-of-care assays for tuberculosis: role of nanotechnology/ microfluidics, Biotechnol Adv, 2013; 31(4): 438-449.

18. Wilson ML. Recent advances in the laboratory detection of Mycobacterium tuberculosis complex and drug resistance. Clin Infect Dis. 2011:52(11):1350-5.

19. Helb D, Jones M, Story E, Boehme C, Wallace E, Ho K, Kop JA, Owens MR, Rodgers R, Banada P, Safi H, Blakemore R, Lan NTN, Jones-López EC, Levi M, Burday M, Ayakaka I, Mugerwa RD, McMillan B, Winn-Deen E, Christel L, Dailey P, Perkins MD, Persing DH, Alland DJ. Rapid detection of Mycobacterium tuberculosis and rifampin resistance by use of on-demand. Near-Patient Technology Clin Microbiol. 2010;48:229-37.

20. Maynard-Smith, L., Larke, N., Peters., J.A. and Lawn, S.D., Diagnostic accuracy of the Xpert MTB/RIF assay for extrapulmonary and pulmonary tuberculosis when testing non-respiratory samples: a systematic review BMC Infect Dis 2014; 14:709 DOl https://doi.org/10.1186/s12879-014-0709-7

21. Van Soolingen D, De Hass PEW, Hermans PWM, Van Embden JDA. DNA fingerprinting of Mycobacterium tuberculosis. Methods Enzymol. 1994;236: 196-205.

22. Mulcahy G. M., Kaminski Z. C., Albanese, E.A. and Sood. R. IS6110 based PCR methods for detection of Mycobacterium tuberculosis. J. Clin. Microbiol. 1996; 34:1348-9.

23. Mao X, Ma Y, Zhang A, Zhang L, Zen L, Liu G. Disposable nucleic acid biosensors based on gold nanoparticle probes and lateral flow strip. Anal Chem. 2009:81:1660-8.

24. Liu C, Yeung C, Chen P, Yeh M, Hou S. Salmonella detection using 165 ribosomal DNA/RNA probe-gold nanoparticles and lateral flow immunoassay. Food Chem. 2013;141:2526-32.

25. Grabar KC, Freeman RG, Hommer MB, Natan MJ. Preparation and characterization of au colloid monolayers. Anal Chem. 1995;67:735-43.

26. Haiss, W., Thanh, N. T. K., Aveyard, J. and . Fernig D. G. Determination of Size and Concentration of Gold Nanoparticles from UV-Vis Spectra, Anal Chem, 2007; 79 (11), 4215-4221,DOl: https://doi.org/10.1021/ac0702084.

27. Mao X, Gurung A, Xu H, Baloda M, He Y, Liu G. Simultaneous detection of nucleic acid and protein using gold nanoparticles and lateral flow device. Anal Sci. 2014;30(6):637-42.

28. Koczula KM, Gallotta A. Lateral flow assays. Essays Biochem. 2016;60:111-20. https://doi.org/10.1042/EBC20150012

29. Chakravorty S, Lee JS, Cho EJ, Roh SS, Smith LE, Lee J, Alland D. Genotypic susceptibility testing of Mycobacterium tuberculosis isolates for amikacin and kanamycin resistance by use of a rapid sloppy molecular Beacon-based assay identifies more cases of low-level drug resistance than phenotypic Lowenstein-Jensen testing. J Clin Microbiol. 2015;53(1):43-51 https://doi. org/10.1128/JCM.02059-14.

30. Karunaratne GHRE, Wijesundera SS, Vidanagama D, Adikaram CP, Perera J. Significance of coexisting mutations on determining the degree of isoniazid resistance in Mycobacterium tuberculosis strains. Microb Drug Resist. 2018; 24(6):844-51.

31. Adikaram CP, Wijesundera SS, Perera J. Geographical profile of rpoB gene mutations in rifampicin resistant Mycobacterium tuberculosis isolates in Sri Lanka. Microb Drug Resist. 2012;18(5):525-30.

\section{Publisher's Note}

Springer Nature remains neutral with regard to jurisdictional claims in published maps and institutional affiliations.

Ready to submit your research? Choose BMC and benefit from:

- fast, convenient online submission

- thorough peer review by experienced researchers in your field

- rapid publication on acceptance

- support for research data, including large and complex data types

- gold Open Access which fosters wider collaboration and increased citations

- maximum visibility for your research: over $100 \mathrm{M}$ website views per year

At BMC, research is always in progress.

Learn more biomedcentral.com/submissions 